\title{
Analisis Performa dan Konsumsi Daya Motor BLDC 350 W pada Prototipe Mobil Listrik Ababil
}

\author{
Jatmiko, Abdul Basith, Agus Ulinuha, Muhammad Afan Muhlasin, Ibnu Shokhibul Khak \\ Teknik Elektro \\ UMS \\ Surakarta, Indonesia \\ jat244@ums.ac.id
}

\begin{abstract}
Abstraksi- Penelitian ini bertujuan untuk menganalisis performa motor listrik dengan jenis BLDC (Brushless DC Motor) atau motor DC tanpa sikat yang di aplikasikan pada prototipe mobil listrik untuk mendapatkan tingkat efisiensi yang tinggi dengan kosumsi daya yang rendah. Mobil listrik tipe prototipe digunakan untuk kompetisi yang mengedepankan desain, transmisi serta konsumsi bahan bakar yang hemat.Pada penelitian ini digunakan motor BLDC 350 watt sebagai penggerak utama. Motor akan dikendalikan melalui rangkaian inverter dengan sumber daya baterai berjenis lithium ion dengan kapasitas 48 volt 10 Ampere hour (Ah). Rangkaian inverter berguna untuk mengubah DC menjadi tegangan $A C$ dengan pengaturan sudut penyulutan berupa hall sensor pada motor BLDC. Throttle berupa variabel resistor berbentuk pedal digunakan untuk mengatur kecepatan motor. Instalasi komponen mobil listrik tipe prototipe terdiri dari pemasangan penggerak utama, aksesoris serta sistem keamanan. Pengujian dilakukan dengan mengukur daya yang diserap oleh motor serta kecepatan dan waktu tempuh pada saat mobil listrik prototipe bergerak. Pada penelitian ini diharapkan hasil pengujian dapat dianalisa untuk mendapatkan kinerja mobil listrik dengan efisiensi tinggi yang hemat energi. Pada penelitian ini dihasilkan performa Motor BLDC akan maksimal dengan penggunaan transimi roda yang paling kecil pada saat motor keadaan starting dan keadaan running menggunakan gigi trasmisi paling tinggi. Pola kemudi dengan melepaskan thottel gas dalam keadaan maksimum akan menghasilkan tingkat keiritan daya yang tinggi dengan konsumsi daya paling rendah yaitu $6.64 \mathrm{Wh} / \mathrm{Km}$ di gigi transimisi 5. Hasil kecepatan rata-rata motor BLDC $350 \mathrm{~W}$ pada prototype mobil listrik yaitu 21 sampai $52 \mathrm{Km} / \mathrm{h}$. Hasil dari penelitian digunakan untuk perbaikan serta meningkatkan performa dalam pembuatan mobil listrik untuk kompetisi maupun komersial.
\end{abstract}

Katakunci-Bldc; Efisiensi; Mobil Listrik

\section{Pendahuluan}

Berbagai kalangan baik akademisi maupun profesional mulai berusaha memikirkan untuk menghemat bahan bakar minyak bumi serta dampak lingkungan yang di akibatkan oleh kendaraan dengan mesin pembakaran dalam. Mobil listrik menjadi solusi atas permasalahan tersebut karena menggunakan energi ramah lingkungan serta tidak menimbulkan polusi [1].Mobil listrik tipe prototipe merupakan wahana yang di gunakan pada kompetisi mobil hemat energi (KMHE) yang bertujuan membuat kendaraan yang irit bahan bakar[2].Dampak yang timbul dari mobil listrik hemat energi adalah lebih hemat biaya.jarak tempuh semakin jauh dan mengurangi waktu pengisian baterai [3].

\section{A. Motor BLDC (Brushless DC Motor)}

Motor BLDC (Brushless DC motor) merupakan Motor DC tanpa sikat merupakan motor yang memiliki efisiensi baik, lebih handal, umur lebih panjang dan cukup mahal. Motor ini memiliki bagian rotor berupa magnet permanen dan bagian stator berupa belitan untuk menghasilkan medan magnet. Pengubahan polaritas motor BLDC dilakukan secara elektronik menggunakan sensor hall-effect dan rotary encoder [4]. Sistem motor DC tanpa sikat mengacu pada konsep rangkaian elektromekanik sistem penggerak yang tanggap dan hemat energi.Sistem tersebut dibangun melalui perpaduan elektromekanik, rangkaian elektronika, sistem sensor dan rangkaian logika atau algoritma kendali mikro [5].

\section{B. Sistem pengendali (inverter)}

Inverter adalah perangkat elektronika yang dipergunakan untuk mengubah tegangan DC (Direct Current) menjadi tegangan AC (Alternating Curent). Tegangan keluaran suatu inverter dapat berupa tegangan AC dengan bentuk gelombang sinus (sinewave), gelombang kotak (square wave) dan sinus modifikasi (sine wave modified)[6]. Sumber tegangan input inverter dapat menggunakan battery, tenagasurya, atau sumber tegangan DC yang lain. Inverter dalam proses konversi tegangan DC menjadi tegangan AC membutuhkan suatu penaik tegangan berupa step up transformer. Rangkaian inverter pada pengendali motor BLDC berupa mosfet dengan penyulutan secara bergantian dan terstruktur [7]. 


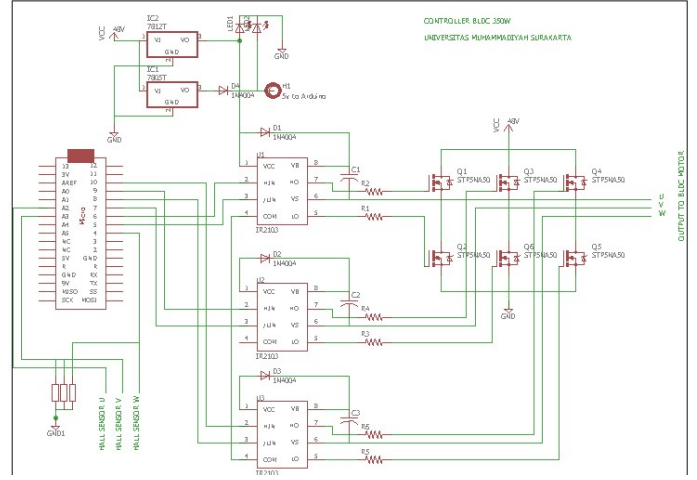

Gambar 1.Skematik pengedali BLDC.

Keluaran inverter berupa tegangan yang dapat diatur dan tegangan yang tetap, Tegangan output yang biasa dihasilkan adalah 5 volt, 36 volt dan 48 volt sesuai dengan kebutuhan tegangan pada nemplate motor. Pengendali Motor BLDC memiliki fungsi utama sebagai sistem pemutar motor BLDC serta mengatur putarannya.Komponen pokok pada controller adalah bagian microprosesor [8].Pada mikro ini sudah terdapat program bagaimana mengendalikan mosfet sesuai urutannya, memberikan eksekusi PWM sesuai masukan berupa pedal gas (Throttel).

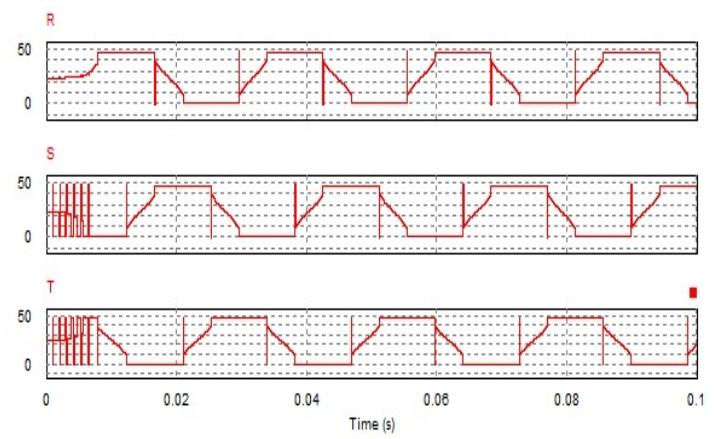

Gambar 2.Gelombang keluaran rangkaian pengendali.

\section{Baterai}

Baterai adalah komponen utama dalam sepeda listrik yang menjadi penyuplai energi listrik.Bisa dikatakan baterai adalah adalah bahan bakar untuk kendaraan listrik. Mobil dengan baterai $L i$-ion hanya memiliki tingkat polusi yang rendah[2]. Dampak lingkungan total yang disebabkan oleh baterai (diukur dalam indikator ramah lingkungan sebesar 99 poin) adalah 15\%. Dampak yang ditimbulkan dengan ekstraksi Lithium untuk komponen Li-ion baterai kurang dari 2,3\% (indikator ramah lingkungan sebesar 9 poin). Kontributor utama beban lingkungan yang disebabkan oleh baterai adalah pasokan tembaga dan aluminium untuk produksi anode dan katode, ditambah kabel atau dibutuhkan sistem manajemen baterai.Keunggulan baterai li -ion yaitu berat yang ringan, pengisian lebih cepat namun harga yang relatif lebih mahal di bandingkan aki. Seperti yang dilakukan oleh tim DEV (Duke
Electric Vehicles) yang menggunakan baterai $\mathrm{Li}$-ion dengan alasan efisien, ringan, dan tahan lama dalam usia sehingga mereka meraih gelar juara di Shell Eco Marathon America. Kebutuhan akan baterai disesuaikan dengan voltase pada motor. Kapasitas baterai akan mempengaruhi lama pengisian dan jarak tempuh yang dapat dijangkau oleh mobil listrik.

\section{Sistem keamanan kelistrikan}

Sistem pengaman sangat diperlukan untuk menunjang keselamatan pengemudi. fuse atau biasa disebut sekering dalam konteks otomotif digunakan untuk melindungi kabel dan peralatan listrik pada kendaraan. Pada prototipe mobil listrik sistem pengaman menggunakan fuse dan emergency button pada sekering otomotif penggunaannya tergantung pada aplikasi tegangan, spesifik, dan nilai arus sirkuit listrik. Sekering otomotif dapat dipasang diblok sekering.Standar untuk sekering otomotif diterbitkan oleh SAE International (sebelumnya dikenal sebagai Society of Automotive Engineers).Sekering otomotif dapat diklasifikasikan menjadi empat kategori berbeda, yaitu antara lain Sekering pisau, Tabung gelas atau jenis Bosch, Fuse limiter[8].Sistem pengaman kedua pada prototype mobil listrik berupa emergency button. Emergency Stop fungsinya untuk menghentikan sistem secara cepat saat keadaan darurat.

\section{Metode}

Tahap penelitian diawali dengan perancangan kebutuhan hardware berupa baterai, motor, sistem pengendali, aksesoris serta kelistrikan pada mobil listrik. Motor listrik menggunakan tipe BLDC (Brushless DC electric motor) dengan daya 350 Watt. Baterai menggunakan $48 \mathrm{~V}$ dengan jenis li-ion dan sistem pengendali berupa inverter.

Pada langkah kedua yaitu perakitan sistem pengendali pada prototipe mobil listrik. Perakitan dilakukan dengan menghubungkan motor ke sistem pengendali (controller). Controller BLDC dihubungkan dengan baterai $48 \mathrm{~V}$ sebagai sumber daya utama. Motor dihubungkan dengan 3 terminal outputsebagai daya utama agar motor dapat bekerja. Pada pengendali BLDC terdapat 3 Sensor Hall Effect untuk mendeteksi sudut penyulutan atau sebagai feedback dan throttel gas untuk mengatur kecepatan motor.

Langkah ketiga yaitu pemasangan aksesoris dan sistem pengaman. Aksesoris dibutuhkan mobil listrik sebagai fitur tambahan penunjang agar mobil siap untuk jalan. Pada mobil listrik prototype aksesoris terdiri dari klakson dan lampu rem. Pemasangan Sistem pengaman juga harus dilakukan dengan menggunakan fuse30A dan Emergency Button.

Tahap terakhir yaitu instalasi kelistrikan serta pengujian alat untuk mencari seberapa besar konsumsi energi yang diserap oleh motor dengan melakukan instrumentasi mobil listrik itu sendiri. Pengujian dilakukan menggunakan watt meter dan yang di pasang parrarel pada sumber daya baterai ke controller. Untuk pengukuran kecepatan mobil listrik di lakukan dengan menggunakan GPS (Global Position System) model Car. 


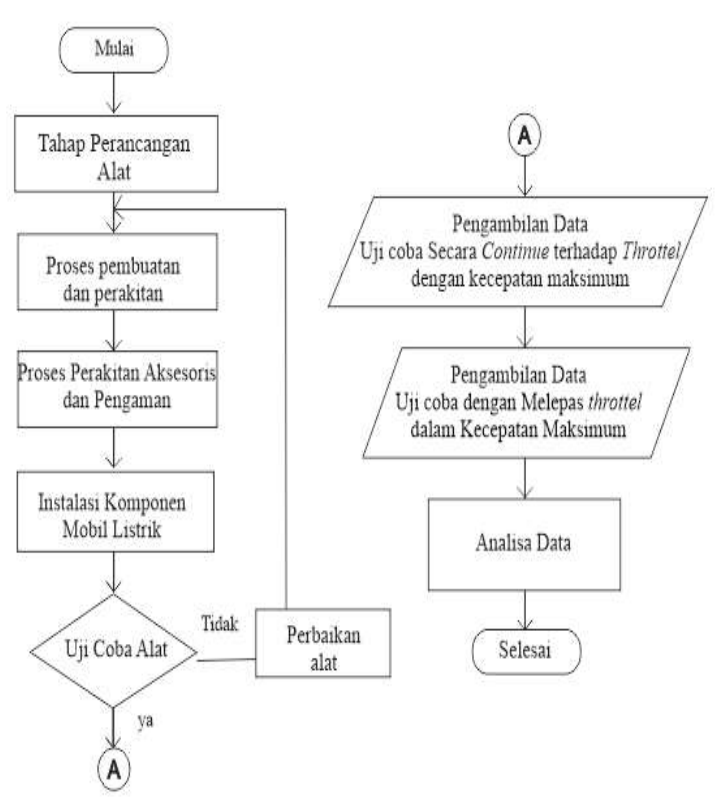

Gambar 3. Alur Penelitian.

\section{Hasil dan Pembahasan}

Setelah dilakukan penelitian dengan langkah yang ditunjukkan pada Gambar 3, percobaan dilakukan dengan mengemudikan mobil secara continue tanpa melepas throttel dan uji coba ke dua melepas throttel dalam keadaan kecepatan maksimum. Hasil Penelitian berupa data kecepatan, waktu tempuh dan konsumsi daya yang ditunjukkan pada tabel 1 .

Tabel 1. Konsumsi Daya, KeCePatan dan WaKtu Tempuh Mobil LISTRIK PROTOTIPE

\begin{tabular}{|c|c|c|c|c|c|}
\hline $\begin{array}{c}\text { Pola } \\
\text { kemudi }\end{array}$ & gigi & $(\mathbf{K m} / \mathbf{h})$ & waktu(s) & $(\mathbf{W h})$ & $(\mathbf{k m})$ \\
\hline \multirow{5}{*}{ Continue } & 1 & 21.0 & 623 & 20.5 & 3.6 \\
\hline & 2 & 27.0 & 450 & 21.2 & 3.4 \\
\hline & 3 & 41.0 & 260 & 12.3 & 3.0 \\
\hline & 4 & 43.0 & 201 & 24.8 & 2.4 \\
\hline & 5 & 51.0 & 255 & 24.0 & 3.6 \\
\hline \multirow{5}{*}{$\begin{array}{c}\text { melepas } \\
\text { throttel } \\
\text { kecepatn } \\
\text { maksimum }\end{array}$} & 1 & 29.0 & 204 & 21.5 & 1.6 \\
\hline & 2 & 43.0 & 205 & 31.2 & 2.4 \\
\hline & 3 & 43.0 & 200 & 24.8 & 2.4 \\
\hline & 4 & 45.0 & 280 & 36.5 & 3.5 \\
\hline & 5 & 53.0 & 187 & 24.0 & 2.8 \\
\hline
\end{tabular}

Penggunaan gigi transmisi roda lebih kecil akan memakan daya lebih besar serta kecepatan yang rendah. Penggunaan gigi roda transmisi terbesar menghasilkan kecepatan yang tinggi dengan kosumsi energi yang rendah. Percobaan ke dua dengan melepaskan throttle dalam keadaan kecepatan maksimum menghasilkan kosumsi energi yang lebih irit dari pada percobaan secara continue pada throttel dengan kecepatan maksimum. Untuk mencari konsumsi daya per jarak tempuh dapat rumuskan sebagai berikut:

$$
\text { Konsumsi daya per } \mathrm{km}=\frac{\text { Kosumsi daya }(\mathrm{Wh})}{\text { Jarak tempuh }(\mathrm{Km})}
$$

Gambar 4 dan 5 menunjukkan grafik perbandingan pola kemudi yang menghasilkan nilai kecepatan rata-rata dengan daya yang di konsumsi oleh motor yang di peroleh dari rumus di atas dan hasil kecepatan rata-rata dan konsumsi daya dengan pola pengemudi yang berbeda.

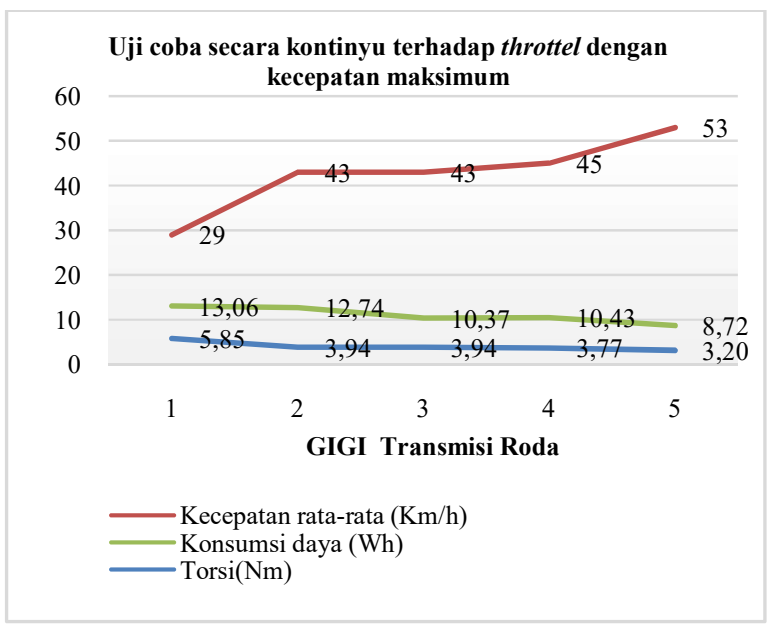

Gambar 4. Grafik percobaan pola kemudi secara kontinyu Pada throttel dengan kecepatan maksimum.

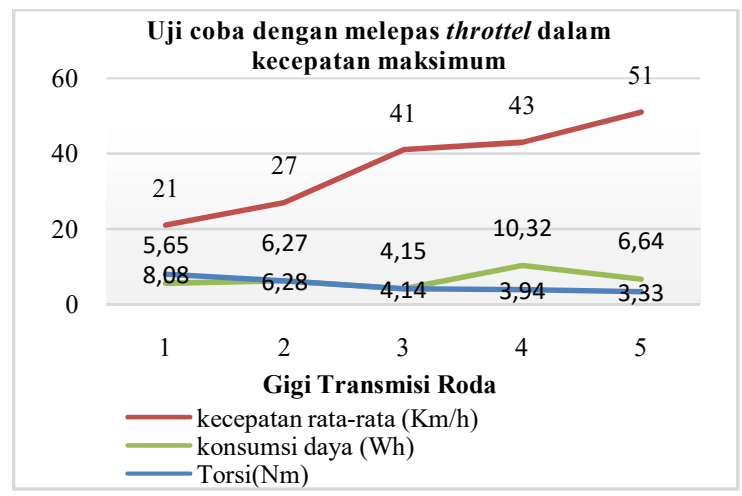

Gambar 5. Grafik percobaan dengan melepas throttel dalam kecepatan maksimum

Untuk menganalisis hasil perbandingan konsumsi daya per kilometer pada pola kemudi dengan melepas throttle dalam kecepatan maksimum terhadap pola kemudi secara continue di sajikan dalam bentuk grafik seperti terlihat pada Gmabr 6 dan 7. 


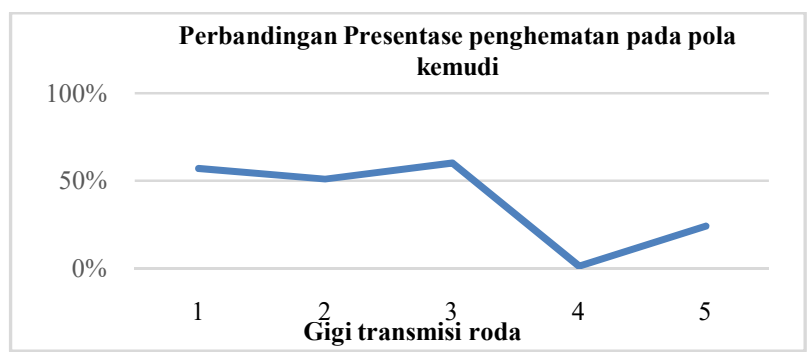

Gambar 6. Persentase perbandingan penghematan pada pola kemudi

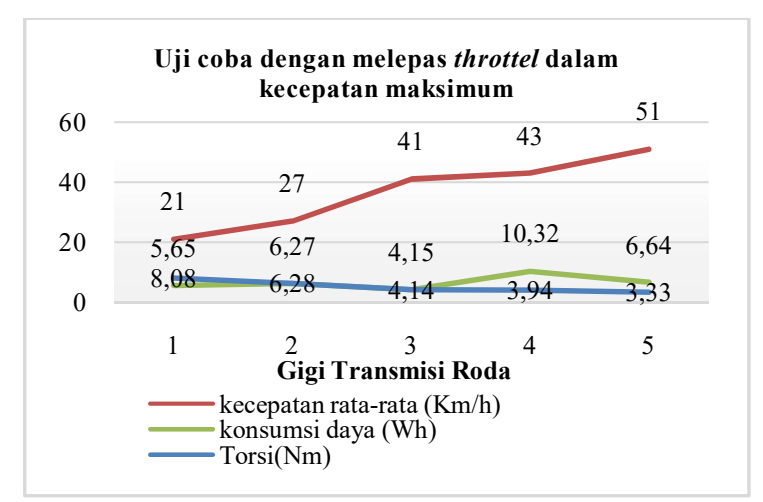

Gambar 7. Grafik percobaan dengan melepas throttel dalam kecepatan maksimum

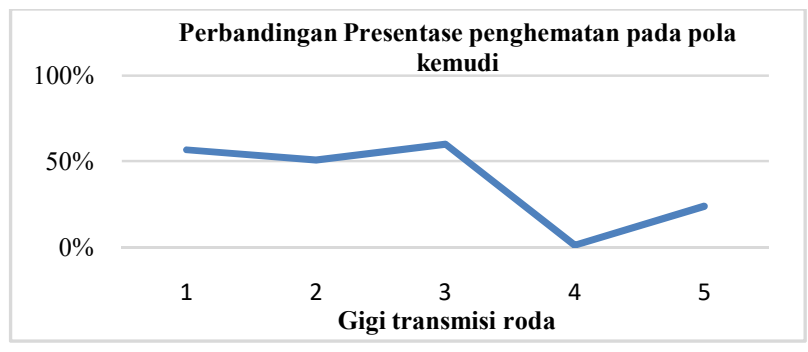

Gambar 8. Persentase perbandingan penghematan pada pola kemudi

Untuk menganalisis Hasil perbandingan konsumsi daya per kilometer pada pola kemudi dengan melepas throttle dalam kecepatan maksimum terhadap pola kemudi secara continue di sajikan dalam bentuk grafik seperti terlihat pada Gambar 8.

\section{KESIMPULAN}

Untuk mendapatkan performa dari motor $B L D C$ dalam prototipe mobil listrik di simpulkan bahwa penggunaan gigi transmisi roda terkecil efektif pada saat motor dalam keadaan starting untuk menghasilkan torsi yang tinggi namun kecepatan rendah dan gigi transmisi roda terbesar digunakan pada saat motor keadaan running untuk mendapatkan kecepatan yang tinggi. Penghematan kosumsi daya motor pada mobil listrik dapat di lakukan dengan mengatur pola kemudi yaitu melepaskan throttle dalam keadaan kecepatan maksimum agar daya tidak dikosumsi oleh motor secara terus menerus.

\section{DAFTAR PUSTAKA}

[1] Beeton, David. Electric Vehicle Business Models Global Perspectives Switzerland : Springer, 2014. Google Books, 2014. berkas PDF. 27 Jun 2018) 1.1 Motor DC tanpa sikat( BLDC)

[2] ristekdikti.2017. Panduan Teknis Kompetisi Mobil Hemat Energi. http://kmhe2017.its.ac.id/.DIKTI. Surabaya

[3] William, anton. Keunggunlan Mobil Listrik https://tekno.tempo.co/read/417918/ini-keunggulan-mobil-listrik. 19 Juli 2012

[4] Azizi, N and Moghaddam, R.K. 2013. Permanent magnet brushless DC motor optimal design and determination of optimum PID controller parameters for the purpose of speed control by using the TLBO optimization algorithm. American Journal of Research Communication, vol. 1, no. 1, pp. $294-313$.

[5] Hidayat. 2014. Pengembangan Hybrid PID-ANFIS (Proportional Integral Derivative Adaptive Neuro Fuzzy Inference Systems) sebagai Pengendali Kecepatan Mesin Arus Searah Tanpa Sikat (MASTS). Desertasi: Universitas Gadjah Mada. Yogyakarta

[6] Anonim. Inverter. https://id.wikipedia.org/wiki/Power_inverter. 29 juni 2018

[7] Daharmawan, Abe. 2009. Pengendalian Motor Brushless DC dengan Metode PWM Sinusoidal Menggunakan ATMEGA16. Skripsi. Universitas Indonesia.

[8] Brilian. Membaca Skema Cara Kerja Kontroller Bldc Motor Listrik.https://www.electricisart-bogipower.com/2014/12/membacaskema-cara-kerja-kontroller.html. 18 maret 2016

[9] Anonim. Fuse. https://en.wikipedia.org/wiki/Fuse_(electrical). 29 juni 2018 